\title{
LA ACTIVIDAD CREDITICIA DE UN HOSPITAL TUROLENSE A TRAVÉS DE LA COMPRA DE CENSALES (1482-1517)
}

\author{
THE FINANCIAL ACTIVITY OF A HOSPITAL IN TERUEL FROM THE VIEWPOINT \\ OF THE PURCHASES REDEEMABLE ANNUITIES (1482-1517)
}

\section{Esther Tello HernándeZ" Institución Milá y Fontanals (CSIC. Barcelona)}

Resumen: Entre todas las posibilidades que ofrece el estudio de las instituciones de beneficencia en el tránsito de la época medieval a la moderna, se encuentra el análisis de los hospitales como instituciones que proporcionan crédito a pequeña escala. Una clara muestra de ello es el hospital de san Juan Bautista y santa María de Villaespesa de Teruel, el cual - entre 1482 y 1517 - compró más de 120 censales a campesinos y artesanos de Teruel y su entorno.

Palabras clave: Corona de Aragón, hospitales, crédito privado.

\begin{abstract}
Being concerned with the analysis of welfare institutions in the Late Middle Ages and the Early Modern Period, this study addresses, at a small scale, the study of hospitals as institutions that participated actively in private debt. To this end, we will go througth the accounts of the hospital of san Juan Bautista and santa María de Villaespesa, located in the city of Teruel. Between 1482 and 1517, these hospitals bought more than 120 redeemable annuities from farmers and artisans of Teruel and its surroundings.
\end{abstract}

Keywords: Crown of Aragon, hospitals, private debt, censales.

* Este estudio ha sido realizado en el marco del proyecto «Financieros al servicio del poder en la Corona de Aragón (S. XIV-XV): métodos, agentes, redes (HAR2011-24839)» y del grupo de investigación de la Generalitat de Cataluña «Renda feudal i fiscalitat a la Catalunya baixmedieval (2014 SGR 1154)». Abreviaturas utilizadas: AHPT $=$ Archivo Histórico Provincial de Teruel. Las cantidades monetarias se expresan en libras, sueldos y dineros jaqueses (1.j., s.j., d.j.). En concreto, el artículo que aquí se presenta es el resultado de la asistencia y participación en dos seminarios que han tenido lugar durante el año 2014, a saber: Seminari d'Estudis de Doctorat y Màster: Els abrils de l'Hospital 2014, coordinado por Antoni Conejo que se desarrolló en Barcelona, y el $1^{\circ}$ Seminari di Studi Dottorali: Alle origini del Welfare, dalla beneficenza all'assistenza (XIV-XIX secc.), que tuvo lugar en el Istituto di Studi sulle Società del Mediterraneo de Nápoles. 


\section{Introducción}

En una publicación reciente T. Huguet escribía que el estudio de los hospitales permite al historiador capturar realidades imposibles de entrever en otros escenarios de la ciudad, poniendo de relieve la necesidad de examinar estas instituciones desde una perspectiva amplia Huguet (2014: 13-27). ${ }^{1}$ Prueba de ello son las numerosas publicaciones y encuentros que desde perspectivas históricas diversas han puesto de manifiesto la fecundidad de los estudios interdisciplinares en el marco de la historia hospitalaria. ${ }^{2}$

Tomando como referencia estos trabajos, en el presente artículo pretendemos centrarnos en el estudio financiero de los hospitales, en general, y en su actividad crediticia, en particular. En concreto, en nuestro caso analizamos cómo el hospital turolense de san Juan Bautista y santa María de Villaespesa compró más de 120 censales entre 1481 y 1517 a campesinos y artesanos de la ciudad de Teruel y sus alrededores, actuando como entidad crediticia a pequeña escala. Todo ello es posible gracias a un libro padrón del notario Alfonso Jiménez que dio a conocer G. Navarro. ${ }^{3}$

Este argumento pone de manifiesto cómo muchas de estas instituciones benéfico-asistenciales pasaron a ser parte integrante de lo que historiográficamente se ha definido por diversos autores como «sociedad del censal». De este modo, muchos de estos organismos fueron beneficiarios de pensiones, llegando incluso a ser una de sus principales fuentes de sustento. ${ }^{4}$ En nuestro

1 Similar idea se desprende también de otra obra conjunta editada, entre otros, por la misma autora arriba mencionada, consecuencia de unas jornadas organizadas por el International Network for the History of Hospitals (INHH) en Barcelona en 2009 (Huguet et alii, 2013).

2 Así queda recogido, por ejemplo, en la publicación de otoño de 2013 de la revista Svmma del Institut de Recerca de Cultures Medievals (Ircum). En la introducción de dicho número, A. Conejo hace un recorrido por numerosos centros de investigación orientados hacia el estudio de estas instituciones (Conejo, 2013: III-VI). Asimismo, diversos congresos anuales nacionales e internacionales impulsan estas investigaciones. Para la historiografía italiana más actual véase la puesta al día llevada a cabo por M. Gazzini, accesible on-line (Gazzini, 2012: 211-237). Por su parte, en este contexto más actual, han sido diversos los autores que han abordado la cuestión de las finanzas hospitalarias, mostrando no sólo la estructura de los ingresos y gastos de estas instituciones, sino también la función crediticia de las mismas (Sánchez, 2014: 177-211; Morelló, 2014: 211-261).

3 Para llevar a cabo esta presentación, la fuente empleada es un libro padrón realizado por el notario Alfonso Jiménez entre 1481 y 1518 (AHPT, Concejo, caja 15, sig. 13). En estos casi 40 años, más de 300 folios escritos nos aportan información sobre los nombramientos de cargos, los bienes del hospital, la compra de censales, los legados píos, etc. (Navarro, 2000: 565-590).

4 Así lo ponen de manifiesto algunos autores para el hospital de la Santa Creu de Barcelona (Morelló, 2014: 211; Sánchez, 2014: 183). De igual manera, resultan interesantes los estudios de P. Bertran, quien trata el recurso a la compra de censales por parte de la Pía Almoina de Lérida ya desde mitad del siglo XIV, 
caso, no pretendemos observar a estos organismos en el marco de la deuda pública, sino más bien en la deuda privada: un hospital que actuó generalmente como rentista de pequeños y medianos labradores y artesanos de Teruel y su entorno. Analizamos entonces el crédito a corto-medio plazo y a pequeña escala a través de la compra de censales, teniendo presente para ello dos aspectos fundamentales; esto es, por un lado, la información financiera que proporciona la documentación, tales como la cantidad y fin del préstamo, las garantías de pago, el plazo de amortización etc., y por otro lado, el análisis de los principales individuos que solicitaron ayuda económica al hospital.

\section{El «crédito caritativo»: apuntes historiográficos}

Como hemos apuntado anteriormente, entre todas las funciones que realizaba el hospital - y que después comentaremos - , aquí nos interesa su función crediticia. En este sentido, lo primero que debe advertirse es que la labor realizada por esta institución debería definirse estrictamente como crédito orientado al consumo, aunque la gestión productiva de la asistencia y la importancia de la Iglesia y de las instituciones caritativas en este ámbito de actuación pública nos pueden llevar a considerarla también, tal como la han denominado algunos autores, una forma de «crédito caritativo». ${ }^{5}$

Ello nos pone en relación asimismo con las actividades de algunos hospitales e instituciones benéficas bajomedievales que han sido estudiados desde el punto de vista financiero como bancos de depósito y proveedores de crédito público. Estos estudios, sobre todo centrados en Italia, muestran el vínculo existente entre la función crediticia y la caridad. En concreto, según G. Piccini, debemos considerar la caridad como un sistema de redistribución de la ri-

destacando la inversión en deuda municipal y atestiguando cómo esta institución incorporó plenamente como recurso el crédito censal, hecho que se acentuó en el siglo XV (Bertran, 2013: 89 y sig.).

5 En este caso, este calificativo de «crédito caritativo» se observa en numerosas obras G. Todeschini orientadas en muchos casos al mercado y a la gestión de la caridad: Todeschini (2007: 17-31, 21; 2004: 186199, 194). Asimismo, resulta interesante la reflexión que realiza el autor sobre la preocupación pública de un problema particular, entendiendo la caridad como una forma de inversión productiva a largo plazo (Todeschini, 2007: 22-25). Sobre este concepto de crédito, para caso castellano y más relacionado con los microcréditos de los montes frumentarios rurarles, véase Castaño (2007: 101-143). Para una síntesis más general y con especial referencia a la Corona de Aragón y a los depósitos frumentarios a finales de la Edad Media, acúdase: Morelló (en prensa). Por último, para el rol desempeñado por la Iglesia en las operaciones de crédito público, véase el estudio de caso del antiguo condado de Bramante, pero con referencias generales en torno al papel crediticio de la Iglesia (Kusman, 2012: 227-249). 
queza, justificado y gestionado desde el propio poder. ${ }^{6}$ De este modo se desarrollaron las fórmulas más variadas de crédito, destacando en el caso italiano el nacimiento de los montes de piedad durante el siglo XV. Estas entidades conjugaban a la perfección la finalidad caritativa con el desarrollo de la actividad crediticia, proporcionando numerario a los grupos sociales más humildes generalmente con la garantía de algún bien.?

Lejos de estas instituciones italianas, en la Corona de Aragón, en general, y en el reino de Aragón, en particular, el estudio de los hospitales medievales ha sido analizado de manera dispar. ${ }^{8}$ En cuanto a su carácter más económico, la función de la Iglesia como institución crediticia se ha puesto de manifiesto sobre todo en algunos hospitales medievales que actuaron como prestamistas de los municipios o de la propia monarquía, tal es el caso del hospital de la Santa Creu de Barcelona como ya hemos indicado. ${ }^{9}$ Aunque efectivamente, otros muchos hospitales e instituciones benéficas desarrollaron su actividad financiera en su entorno más inmediato y en relación con el tema que aquí nos ocupa; instituciones que canalizaron buena parte de los ingresos procedentes de terceros en rentas perpetuas, tal como muestra M. Aventín para el hospital de Sant Celoni en el siglo XV. ${ }^{10}$

Asimismo, - aunque no podamos hablar propiamente de función crediticia en su origen - también encontramos a estas instituciones creando cajas de depósito como serían las Quotidianes Distribucions, estudiadas en algunos lugares de Cataluña. Muchas de estas caixas, ya avanzada la época moderna, sirvieron claramente al crédito censal, tal como expone Ll. Ferrer i Alòs en la Manresa del siglo XVIII. ${ }^{11}$

6 Piccinni (2012: 22; 2010: 93-96). Para la Corona de Aragón, véase entre otros: Gallent (1984: 75$88)$.

7 Para el asunto del crédito y del nacimiento de los montes de piedad, véase para ámbito italiano: Avallone (2007: 71 y sig.). Sobre la actividad crediticia del hospital di Santa Maria de Siena hasta la creación del monte pio sienés en 1472, y en concreto su actuación como banco de depósito, prestamista del Estado, véase Piccinni (2012: 284-290). Más en relación con los montes de piedad y su finalidad caritativa, véase entre otros: Muzzarelli (2010: 101-111; 2005). Asimismo, acúdase a los artículos más novedosos al respecto de autores como P. Avallone, T. Fanfani o V. Zamagni.

8 Para una breve revisión historiográfica de la Corona de Aragón, véase el reciente libro: Huguet et alii (2014). Para una puesta al día de la situación en el reino de Aragón, véase Pérez (2013: 292-294).

9 Sánchez (2014: 177-211). Asimismo, analizando el mismo hospital, J. Morelló profundiza en la compra de censales desde la década de 1370 (Morelló, 2014: 211-261).

10 Aventín (1996: 404-408). La autora señala cómo el hospital de Sant Celoni acabó siendo, en el siglo $\mathrm{XV}$, una importante institución financiera por la labor que realizaba en esta villa-mercado.

11 Sobre las Quotidianes Distribucions en época medieval, véase Galera (1997: 11-45), donde trata un proceso contra el rector de Sant Miquel de Cardona acusado de robar 25 1.b de la caja que tenían en 
Y es que la función crediticia de la Iglesia y de las demás instituciones benéfico-asistenciales aumentó de forma importante en época moderna, especialmente a raíz del progresivo traspaso de la deuda censal al clero, lo que explica en muchos casos la primacía de la Iglesia en el mercado censal. ${ }^{12}$ Además los hospitales e iglesias continuaron actuando como acreedores privados, comprando censales a pequeños agricultores y artesanos que debían hacer frente al pago de deudas, dotes o legítimas, gastos de labranza, etc. ${ }^{13}$

\section{La función crediticia del Hospital de san Juan Bautista de Teruel}

Atendiendo al hospital que aquí nos interesa, tenemos noticias de su existencia desde 1270, bajo la invocación de san Juan Bautista, uniéndosele en el siglo XV la de santa María de Villaespesa. ${ }^{14}$ Parece ser que en origen fue un hospital parroquial y que en 1572 adquirió un carácter municipal, pasando a denominarse Hospital General de la Asunción. Durante todo este tiempo estuvo situado en la plaza de san Juan, hasta que en 1938 fue destruido durante la Guerra Civil. ${ }^{15}$ Su evolución durante la Edad Moderna ha sido estudiada sobre todo desde el punto de vista de la renta agraria, observándose también la preponderancia adquirida por esta institución en el marco urbano. Concretamente, se ha mostrado como el Hospital General de la Asunción adquirió en el Antiguo Régimen un papel predominante en el mercado de la producción agrícola, especialmente por su capacidad de disponer de grano. ${ }^{16}$

depósito las rentas de los religiosos de la iglesia. Ya para época moderna resulta interesante como L1. Ferrer analiza la función censalista de la Seu de Manresa, cuyos ingresos principales provenían de fundaciones y limosnas, y se invertían en censales y tierras (Ferrer, 1986: 7-46).

12 Ferrer (1983: 105-106). En este mismo artículo también se trata ampliamente la finalidad de la venta de los censales creados por los campesinos y artesanos.

13 Sobre el papel del crédito rural en época moderna, véase: Tello (1994: 9-37) y Mateos (1999: 81-84). Para Aragón, atiéndase además a Latorre (1992: 77-86) y Atienza (1987: 67-104).

14 Así, el 1 de julio de 1505 los regidores y procurador de Teruel, comunicaron esta fusión para poder atender a los pobres, para lo cual se ruega que se concedan indulgencias a las casas de la ciudad: AHPT, Concejo 32, 47.

15 Navarro (2001: 566). Además, según A. Gargallo sería así el único hospital parroquial documentado en Teruel en este periodo (Gargallo, 1997: 201). Por ello, resultaría interesante reflexionar sobre la evolución de éste y otros hospitales entre el marco del poder municipal y parroquial, reconociendo el interés público de estas instituciones, tanto a nivel político como económico. Para este asunto, véase de nuevo nota 8, y en especial el artículo de G. Piccinni. Para Aragón, sirva también como referencia Rodrigo (1995: 287-317).

16 Latorre (2010: 71-98). 
En el periodo analizado (1482-1517), el hospital era gestionado por la cofradía homónima, la cual regía su administración a través de la Junta de los Doce. Los cargos eran elegidos anualmente en la fiesta de la Virgen de septiembre. Además, en san Juan se nombraba a dos limosneros, a dos o tres auditores y al hospitalero. Este último era un agente fundamental para el asunto que aquí analizamos, por ser él quien compraba los censales en nombre del hospital y quien exigía su cobro. Todos ellos eran cofrades, laicos y - en los casos conocidos - se documentaban como labradores o artesanos de Teruel. En 1503, debido a la gran carga que suponía la recaudación de las pensiones censales, la junta decidió pagar un salario de $80 \mathrm{~s} . \mathrm{j}$. al hospitalero por su labor. Dos años más tarde, el 1 de junio de 1505, la junta designó como recaudador de las pensiones al notario turolense Juan Martínez, y se le asignaron los 80 s.j anuales. Con todo, el hospitalero siguió siendo el comprador nominal y, en todos los casos estudiados, el hospital de san Juan Bautista y santa María de Villaespesa asumió la titularidad única de las pensiones. ${ }^{17}$

Por lo que respecta a la financiación del hospital, al no disponer de libros de rentas, - al menos para el periodo analizado - no podemos establecer jerarquías entre los ingresos y los gastos, pero a través de la fuente analizada sí se pueden conocer algunos de los mecanismos mediante los que se sufragaba la institución.

Como es sabido, los estudios referentes a la financiación de los hospitales son numerosos y heterogéneos, y van desde los clásicos trabajos de U. Lindgren hasta los artículos más novedosos arriba mencionados..$^{18}$ Todos ellos analizan los ingresos y los gastos de estas instituciones. Por una parte, los gastos

17 Gracias a las ordinaciones de otros hospitales, conocemos también como se administraban y gestionaban las diferentes rentas a través del hospitalero o del oidor de cuentas. Así, en el hospital de Nuestra Señora de Gracia de Zaragoza, el racional o el oidor de cuentas tenía copia del cabreo de las rentas, censales y derechos del hospital, que debían de ser además testificado por el notario del propio hospital (Monterde, 2008: 523 y 526). Un caso similar en cuanto al racional u oidor de cuentas, se documenta en el hospital de la Santa Creu de Barcelona (Sánchez, 2014: 179 nota 6). En otras instituciones religiosas también se nombró un laico para recibir las pensiones censales, tal es el caso del monasterio de La Saïdia de Valencia, donde un síndico realizó esta labor (Viciano, 1991: 112). Con todo, analizar esta figura desbordaría el fin y objetivos de este trabajo.

18 Como punto de partida para el estudio financiero de los hospitales, véase: Lindgren (1987: 525-532) y Conejo (2010: 437-445, 440). Este último observa cómo los gastos a los que hicieron frente algunas de estas instituciones eran muy superiores a los ingresos que recibían. Para el caso valenciano: Rubio (1984: 91-92), quien basándose en los ingresos del hospital de Clapers observa que sus rentas patrimoniales suponían el 95\% del total. Para una tipología de los ingresos y gastos de estas instituciones y su clasificación más funcional, véase Sánchez (2014). 
Cuadro 1. Cofrades hospitaleros entre 1482-1517

\begin{tabular}{|l|l|}
\hline Nombre del hospitalero* $^{*}$ & Ejercicio del cargo \\
\hline Martín García & 1482 \\
\hline Francisco de Ovón & 1483 \\
\hline Andrés de Valdecebro & $1483-1486 / 1488 / 1492$ \\
\hline Juan Calvo & 1486 \\
\hline Ferrando de Llestas & 1486 \\
\hline Juan Muñoz & $1486-1487$ \\
\hline Bartolomé de la Mata & 1488 \\
\hline Pedro Ortiz & $1490-1491$ \\
\hline Pedro de Villaespesa & 1491 \\
\hline Domingo Roldán & 1493 \\
\hline Juan de Carrión & $1493-1494$ \\
\hline Luis Pérez, argentero & 1495 \\
\hline Pascual Gil Asensio & $1496-1497$ \\
\hline Lorenzo Bernabé, soguero & $1497-1498$ \\
\hline Alejandro Cañegral & 1500 \\
\hline Bernardo Escudero & 1500 \\
\hline Antón de Torremocha & $1501-1502$ \\
\hline Francisco de Alda, labrador & 1502 \\
\hline Gil Ambel, espadero & $1503-1504$ \\
\hline Miguel de la Vega, labrador y cubero & $1504-1505$ \\
\hline Juan de Oviedo, cardero & 1505 \\
\hline Martín de Báguena, pelaire & 1507 \\
\hline Pedro Ferreruela, labrador & $1506-1517$ \\
\hline & \\
\hline
\end{tabular}

* Se indica el oficio del hospitalero en los casos documentados en el propio libro padrón. Listado completo de cofrades que ocuparon cargos de administración en el hospital, en: Navarro (2000: 578-585).

a los que debían hacer frente estos organismos son de sobra conocidos: asistencia a pobres y enfermos, dotes, mantenimiento del hospital, pago de salarios, etc. Por otra parte, atendiendo a los ingresos, todos los autores recalcan 
la importancia de las limosnas y los legados píos que recibían estas instituciones, y el hospital de santa María no fue una excepción. ${ }^{19}$

Sin embargo, en el caso turolense, cabría reflexionar también sobre la importancia de los ingresos patrimoniales del hospital, incluyendo aquí los censales y otras rentas de tierras y censos enfitéuticos. No en vano parte de los ingresos provenientes de limosnas y legados píos se invertían en el mercado censal, favoreciendo que el dinero y las rentas circulasen continuamente. ${ }^{20} \mathrm{Un}$ ejemplo de ello lo encontramos en 1483, cuando Pedro Genés, vecino de Teruel, dejó como herencia al hospital una era y unos utensilios de bodega. Tres años más tarde, el 23 de febrero de 1486, el labrador Jaime Esteban y su mujer vendieron al hospital un censal por 460 s.j., justo después de haber comprado al hospital las tierras y utensilios de bodega que había dejado como legado el susodicho Pedro Genés.

Lamentablemente, nos es imposible calcular la cantidad que el hospital recibía anualmente de las pensiones censales, si bien es cierto que disponemos de algún dato puntual, tal como señala G. Navarro; así, en el ejercicio de 1516-1517, el hospital cobró de pensiones y censos 1.532 s. 9 d.j., según aparece en un documento de noviembre de ese año. ${ }^{21}$

Y tampoco podemos determinar con absoluta seguridad con qué finalidad se compraban estas pensiones censales: ¿se convirtió en uno de los principales cometidos del hospital?, ¿se realizaba conscientemente como forma de crédito caritativo o constituía simplemente un ingreso más de la institución, además de una renta segura y continua? y ¿qué importancia alcanzó su gestión en el conjunto de la administración del hospital? ${ }^{22}$

\section{La compra de censales como fuente de financiación del hospital}

Como es sabido, un censal se puede definir a grandes rasgos como un contrato de compraventa con pacto de retro, donde el vendedor vendía al compra-

19 Navarro (2000: 575-577).

20 Para ello resulta esclarecedor el artículo de Gabriella Piccinni, quien - aunque centrada en la actividad femenina - observa en qué y cómo se invertía parte del dinero recibido en el hospital de Santa Maria della Scala en el segundo tercio del siglo XIV (Piccinni, 2012: 121-149).

21 Navarro (2000: 576). Con todo, como es sabido, la financiación a través de la compra de rentas llegó a alcanzar mucha importancia en otras instituciones tal como hemos apuntado anteriormente (Comelles, 2013: 190-191).

22 Para reflexionar sobre esta idea y sobre todo del asunto referente a las rentas patrimoniales de hospitales e instituciones benéfico-asistenciales en general, véase Pastore; Garbellotti (2001). 
dor el derecho a percibir periódicamente una pensión por un precio determinado. Habitualmente, se trataba de un préstamo encubierto, donde el vendedor era el deudor, el comprador era el acreedor y la pensión era el resultado de aplicar un determinado tipo de interés en el precio de la venta. ${ }^{23}$ En todos estos casos, la persona que recibía ese préstamo, vendedor del censo o pensión, establecía como garantía alguna de las propiedades que poseía. En la documentación analizada, estos censos se cargaban sobre viñas y tierras, y pocas veces casas particulares, aunque también estaban obligados la totalidad de sus bienes, a los que se acudía en caso de impago.$^{24}$ Por su parte, la carta de gracia o pacto de retrovenda, establecía que la deuda era redimible, siendo de gran interés observar cuánto tiempo transcurría entre la venta de la pensión y la luición del censal, momento en el cual se cancelaba el contrato. Cabe advertir que, en estos casos, la fecha de la devolución del capital no estaba prevista, sino que se encontraba sujeta a la voluntad del vendedor del censo. Y es que, como ha sido tantas veces señalado por autores como A. Furió, el acreedor no buscaría tanto la amortización del préstamo, como la extracción de rentas de forma continua y segura..$^{25}$

Para el caso aquí estudiado, el recurso a los censales y otros sistemas de crédito era - en palabras de J.V. García Marsilla - una tabla de salvación que aplazaba los problemas más urgentes y contribuían a preservar la estabilidad social. Observamos entonces como las familias entraron en el mercado de la deuda, a la par que se producía una transformación comercial y financiera que dotaba al sistema de confianza y estabilidad. ${ }^{26}$

Además, debemos tener presente que en este periodo el censal ya estaba legitimado moral y jurídicamente. Recordemos que a mediados del siglo XV, el propio papado autorizó explícitamente el uso del censal. Aunque, más allá

23 En este caso, nos hemos servido de las definiciones de P. Ortí (2007: 261). Sobre el proceso de venta de restas, véase una buena síntesis en Rubio (2007: 239-255).

24 Cargar rentas sobre tierras más que sobre casas correspondería, en palabras de J.V. García Marsilla, a una estrategia propia de los endeudados, que buscaban preservar - en última instancia - el propio domicilio (García, 2002: 182-183). Sobre la actuación ante situaciones de impago, véase el caso de Sueca, donde se observa cómo se llevaba a cabo el proceso judicial contra los supuestamente insolventes (Furió et alii, 1993: 160-165, 162).

25 Furió (1993: 503) y García Marsilla (2002: 188-189).

26 En general, para conocer las particularidades europeas, véase el conjunto de estudios editado por M. Berthe (1998). En especial en dicho volumen el artículo de A. Furió, en el cual se refiere a la difusión del crédito en la Península Ibérica, en general, y a Aragón en particular (Furió, 1998: 139-168, 151-152 y 161-163). También para Aragón, resulta sugerente el análisis de J.A. Sesma en torno a la revolución comercial (Sesma, 2013: 43-95). 
del consentimiento pontificio, lo que realmente debe tenerse en cuenta es que la justificación de los censales así como de otras prácticas comerciales no era otra cosa que un mecanismo de defensa también para la propia Iglesia, que se benefició ampliamente de ellos. ${ }^{27}$ En el caso que aquí nos atañe, las rentas perpetuas o vitalicias vendidas a particulares se caracterizan por ser un instrumento a corto o muy corto plazo, de pequeñas cantidades que permitieron a la Iglesia introducirse rápidamente en el mercado censal. ${ }^{28}$

Así pues, es en este contexto que debemos analizar la compra de rentas por parte del Hospital de san Juan que, como hemos dicho, podemos rastrear gracias al libro padrón del notario Alfonso Jiménez. Esta fuente incluye la documentación originada desde la creación de la deuda hasta - en el mejor de los casos - su liquidación. Así, tras el documento de compraventa del censal, aparecía el ápoca: un recibo del deudor por el cual reconocía haber recibido el precio estipulado por la renta. En todos los casos, seguía también la carta de gracia, que no era otra cosa que la promesa del comprador de dar por finalizado el contrato en el momento que el vendedor le restituyese la cantidad prestada. Cuando esto ocurría, era anotado al margen del documento principal o en un documento posterior, dando lugar a la luición o redención del censal. En ese momento, el deudor retornaba la cantidad debida al prestamista, aportando información sobre su compra, los cambios de titularidad o las reducciones de intereses si éstas existían. Con ello, se daba por finalizado el censal.

A partir de todos estos instrumentos, podemos abordar dos grandes cuestiones. Por una parte, la documentación asociada a la compraventa de censales nos muestra las características de las rentas vendidas por el hospital: en primer lugar, el número de pensiones documentadas a lo largo de los años; en segundo lugar, la cantidad prestada y la finalidad de la misma; y por último, el tipo de interés y la quitación del censal. Por otra parte, la información aportada por

27 Mediante la bula Regimini Universalis expedida por Martín V en 1425 y confirmada 20 años después, se permitió la compra-venta de rentas por aprobación del papado. Para mayor información sobre este asunto y cómo se trató la cuestión en la Corona de Aragón, véase los estudios de J. Hernando donde se analiza este tema a través de numerosa documentación notarial, pero -en este caso-sobre todo centrado en cómo abordan esta cuestión autores como Francesc Eiximenis o Bernat de Puigcercós (Hernando, 2007, 213-238). Una visión más general desde el punto de vista del campesinado y artesanado en Comelles (2014: 188-191 y 194).

28 J.V. García Marsilla, en su obra tantas veces citada, trata como se justificó asimismo desde el poder civil y religioso el uso del censal. En concreto atiende a este asunto a través la perspectiva municipal (García Marsilla, 2002: 219 y sig.). 
la fuente estudiada nos permite reflexionar sobre la sociología del crédito censal, analizando el perfil de los principales censatarios del hospital.

\subsection{Características de las rentas censales}

En total, entre 1482 y 1517 documentamos 128 ventas de censales, repartidos de forma variable a lo largo de estos años. Habitualmente, la compra media de censales se situó entre 1 y 5 operaciones al año. Entre 1489 y 1499 , sin embargo, el hospital no adquirió ningún censal. Y hay momentos críticos como los años 1511, 1514 y 1517 con 13, 12 y 11 compras del hospital respectivamente, y los años 1486, 1497 y 1510 con 8 ventas en 1486 y 1510, y 9 en 1497.
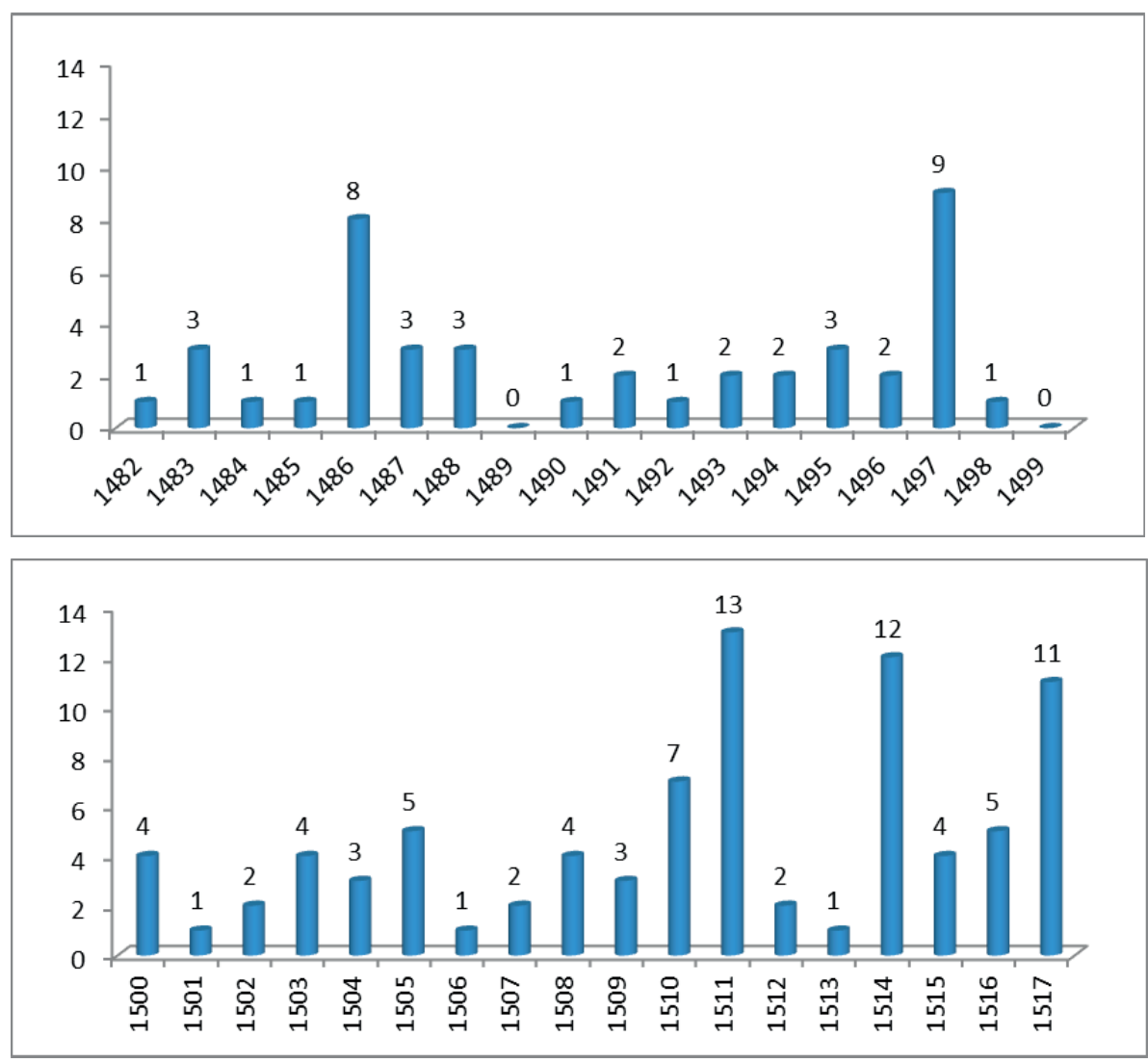

Gráfico 1. Censales comprados por el hospital entre 1482 y 1517. 
Cabría preguntarse a qué se debió este aumento y si estuvo relacionada con una mayor capacidad crediticia del hospital o bien con una creciente demanda de préstamos por parte de las gentes de Teruel. Es más, debemos reparar también - tal como se verá posteriormente - que el mayor número de quitaciones de censales se realizaron asimismo en estos años, en especial entre 1509 y 1517, aunque esto quizá se deba a que conservamos información documental más abundante en la primera parte del siglo XV.

Como decíamos, otra perspectiva de análisis se refiere a la cantidad prestada, la finalidad y la evolución del censo. Podemos establecer que la cantidad demandada osciló por lo general entre 50 y $1000 \mathrm{~s} . j$, aunque el 75\% de los préstamos se concentraron entre 100 y 300 s.j. De este modo, nos encontramos ante préstamos intermedios a los que solían recurrir las familias campesinas y artesanas para hacer frente a numerosos gastos más o menos ordinarios, como la compra de bestias, utillaje o simientes así como otros asuntos relacionados con la tierra y la mejora de la capacidad productiva e inversión en las empresas familiares, tal como se observa coetáneamente en otros territorios. ${ }^{29}$ Por debajo de 100 s.j., encontramos algún préstamo puntual de 50 o 60 s.j., y por encima de los $300 \mathrm{s.j}$, hallamos 19 pensiones, cuyo precio se sitúa entre los 300 y 500 s.j., destacando dos préstamos de 500 s.j., otros dos de 600 s.j y uno de 1.000 s.j. A excepción del préstamo de 1.000 s.j., que corresponde a la iglesia de san Jaime de Teruel y que después comentaremos, el resto de censatarios son campesinos y artesanos de Teruel, Cella, Villel y la Puebla de Valverde. Del mismo modo, también podemos destacar que el año 1514, cuando precisamente se compraron tres de los censales más elevados, el de 1.000 s.j y dos de 600 s.j., ello supuso un desembolso para el hospital entre marzo y diciembre de 2.200 s.j., una cantidad relativamente elevada si la comparamos con la pensión anual de 150 s.j., al 6,8\% de interés, que recibirían en contrapartida.

La finalidad de estos préstamos casi nunca consta en la documentación, aunque en ocasiones podemos deducir su uso. Así, teniendo presente la función piadosa del hospital y su vinculación con la cofradía de san Juan, no es de extrañar que algunos de los préstamos tuviesen como fin el pago de una misa que un familiar difunto ordenaba en su testamento. Tal como dice M.

29 Así por ejemplo, el caso de Sueca es bastante significativo en cuanto a las empresas familiares y la capacidad productiva (Furió et alii, 1993: 131). 


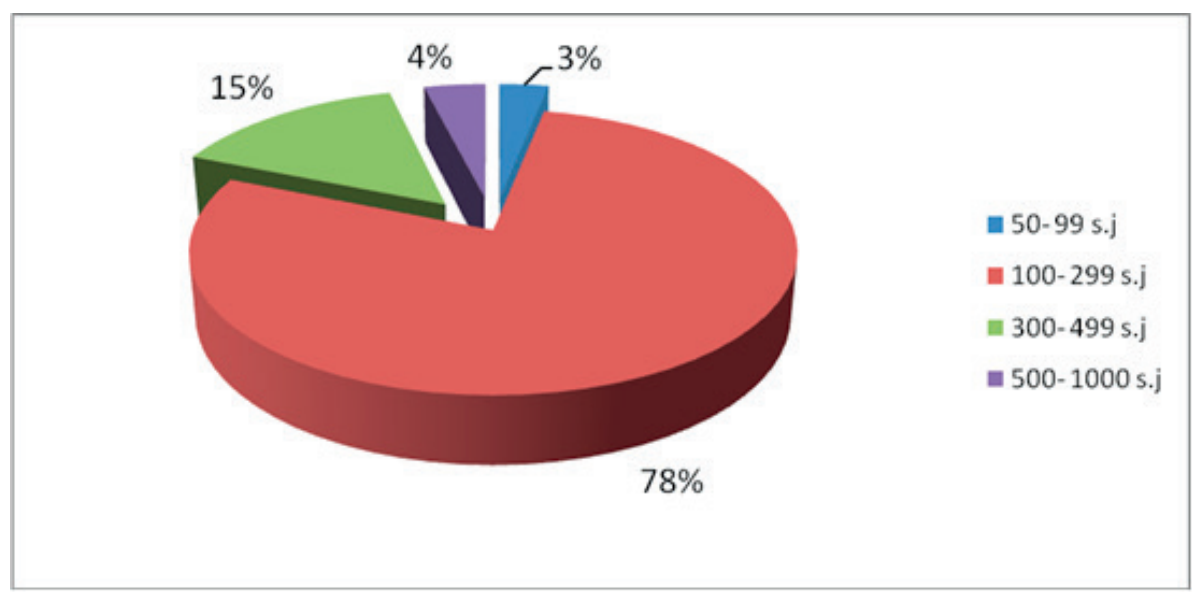

Gráfico 2. Volumen de los préstamos otorgados por el hospital

Aventín, estaríamos también ante un mercado que ayuda al buen morir..$^{30}$ De este modo, los herederos encargados de cumplir las mandas piadosas del testador, al no tener recursos económicos suficientes, vendían un censal al hospital para cumplir con la disposición de celebrar la misa por el alma del difunto. Recordemos además, que al ser un hospital regido por una cofradía, las misas se encargaban generalmente a la misma corporación y normalmente tenían un precio de 120 sueldos. Así, en numerosas ocasiones se puede observar cómo, tras un albarán donde el hospitalero reconocía haber recibido cierta cantidad para hacer frente al pago de una o varias misas, los albaceas y familiares del difunto vendían un censal. Esto ocurrió por ejemplo en 1483, cuando Pedro Lidón y su mujer Catalina vendieron un censal de 120 s.j para celebrar una misa por la madre de ella en la iglesia de San Juan. ${ }^{31}$

Sin embargo, como hemos señalado, en la mayoría de los casos no conocemos la causa última de la venta del censal, aunque - como es de esperar- en muchas ocasiones estaría destinado a asuntos relacionados con la producción agrícola y empresas artesanales, tal como apuntábamos en la página anterior. Más allá de esto, no documentamos la compra de tierras o casas particulares, u otras formas de préstamo encubierto para el mercado inmobiliario y que justifi-

30 Sobre la venta de rentas como «mercado de salvación», véase el interesante artículo de Aventín (2014: 53-73).

31 Más ejemplos sobre la venta de censales para la celebración de misas, en Tello (2013: 162-165). 
caría la demanda de capitales más importantes ${ }^{32}$ Sea como fuere, todo ello parece estar orientado al desarrollo - de un modo u otro- de los sectores productivos, esto es, de las empresas campesinas y artesanales. ${ }^{33}$ Asimismo, y dejando de lado los censales para la celebración de misas y para asuntos laborales, cabría suponer que estos préstamos también pudieron estar dirigidos a la amortización de deudas anteriores, o bien a un asunto económico de gran importancia para las familias campesinas como eran las dotes para el matrimonio. ${ }^{34}$

Otro de los aspectos interesantes a propósito del censal es comprobar cuándo se liquidó la deuda. Al encontrarnos con una documentación parcial, es imposible reconstruir un patrón claro en los procesos de compraventa de censales en todas las operaciones.

Como decíamos, en los casos que se liquidaba la deuda aparecía un nuevo contrato de compraventa o quitamiento por el cual se redimía el débito. A través de estos documentos podemos observar bastante bien como la amortización de algunos préstamos - sobre todo aquellos que oscilaban entre 100 y $400 \mathrm{s.j}-$, se producía al cabo de uno a cuatro años de media. Estas pensiones por debajo de los $400 \mathrm{s.j}$ suponían el $44 \%$ del total de censales que hemos podido documentar completamente hasta su finalización (Vid. Cuadro 2). Esto suponía que, teniendo presente un interés medio de en torno a un $8,33 \%$, un préstamo de $100 \mathrm{~s} . j$. sería amortizado por el hospital en 12 años, tras los cuales ya solo cobrando los interés habrían recuperado la cantidad inicial. Así le ocurrió al labrador Luis Galcerán, quien en agosto de 1500 vendió un censal por precio de 100 s.j que devolvió íntegro en noviembre de 1512 habiendo pagado de interés $100 \mathrm{s.j}$, más los $100 \mathrm{s.j}$ del préstamo originario.

Con todo, aunque en la mayoría de los casos se tratara de una deuda a corto plazo, también cabe señalar que ocho censales tuvieron una vida de más de 20 años; y pese a que esto no es lo habitual, los beneficios del hospital en estos casos resultan evidentes. De este modo, en 1486 se compró un censal por 460 s.j que finalizó en 1510, habiendo recibido de interés más de $900 \mathrm{s.j}$ en total.

32 García Marsilla (2002: 208-209).

33 Por ello sería de gran interés observar asimismo la geografía del paisaje, ya que la documentación nos proporciona gran información sobre las tierras cargadas, sus lindes y las hipotecas de las mismas. Para mayor información sobre este asunto, véase: Navarro (2006: 425-246) y Muñoz (2006: 193-207).

34 Para el caso de la amortización de deudas anteriores, véase el caso valenciano que estudian Furió et alii (1993: 131). Sobre la venta de censales para hacer frente a las dotes, atiéndase a Reixach (2013: 49-66), donde a través del ejemplo de Gerona establece diferentes categorías de venta de censales para dotar a las hijas. 
Sin duda, este ejemplo es excepcional y en la mayoría de los casos los réditos no alcanzaron la cantidad prestada, o si lo hicieron no sobrepasaron los $250 \mathrm{~s} . \mathrm{j}$ en los documentos analizados, ya que - como hemos señalado- en la mayoría de los casos analizados, estos préstamos tuvieron una vida mucho más breve No obstante, nos hallamos ante una muestra más de que el acreedor no buscaba recuperar el capital rápidamente, sino asegurarse el cobro de una pensión anual durante el máximo periodo de tiempo.

Atendiendo al interés del préstamo, en la mayoría de los casos presentados ascendía a 8 s. 4 d.j por 100 s.j (un 8,33 \%). Este porcentaje se estableció el 2 de septiembre de 1381 - en el primer documento del libro padrón-, cuando en una reunión de la junta se plantearon reducir el interés (que estaba instaurado en $10 \mathrm{s.j}$ por $100 \mathrm{s.j}$ ), alegando que las rentas de otras instituciones crediticias eran menos gravosas que las del hospital ${ }^{35}$. Por ello, la junta decidió bajar el tipo hasta el porcentaje que debía ser común en la ciudad para estos préstamos, sin que pudiera elevarse bajo ningún pretexto. En este caso, debemos tener presente que los intereses de estos censales oscilaban entre el 7,14 y el 8,33\% en el periodo estudiado, aunque había fuertes diferencias territoriales. ${ }^{36}$

Con todo, hay alguna excepción a este interés más o menos fijo. El caso más claro lo observamos en la compra de un censal el 3 de diciembre de 1514, que tuvo lugar en la iglesia de san Jaime de Teruel, donde el vicario, con la finalidad de pagar dos campanas y otros gastos de la fábrica del templo, vendió una pensión de 60 s.j por una cantidad de 1.000 s.j al hospitalero Pedro Ferrer, a pagar anualmente en la fiesta de santa Bárbara (esto es, a un interés de un 6\%). En el mismo documento se alude a que el hospital fue quien le ofreció un interés más bajo y que el vicario y los clérigos «no hayan trovado quien más función les fiziesse ni más barato». ${ }^{37}$ De aquí se deduce que según el vendedor o la cantidad se podía negociar un interés menor, quizá también porque su amortización se podría extender más en el tiempo o por la condición eclesiástica del vendedor. Pero no podemos contrastar esta hipótesis ni en este ni en otros casos, ya que en más de la mitad de los préstamos documentados no tenemos noticia de cuándo fueron luidos.

35 Navarro (2000: 575)

36 Furió et alii (1993: 120). Sin embargo, otras instituciones hospitalarias, como el hospital de la Santa Creu de Barcelona, compraban pensiones a un interés de en torno al 4-5\%, siendo en este caso los intereses más bajos aquellos que eran pagados por instituciones públicas, en Morelló (2014: 223).

37 Navarro (2000: 575). 
Sería de enorme interés analizar la documentación notarial y entrar, asimismo, en el asunto de la morosidad y de los problemas de pago sufridos por los campesinos y artesanos que eran incapaces de redimir la deuda por diversas circunstancias. Cabe advertir, sin embargo, que tan sólo excepcionalmente se llegaba al último eslabón del proceso de ejecución por deudas y se perdían los derechos de la propiedad sobre la que se había cargado el censal. Este postrero paso suponía la emisión de cartas ejecutorias y, en última instancia, la confiscación de las tierras puestas en garantía por los deudores, cuya propiedad era traspasada al hospital cuando se acumulaba durante largo tiempo el impago de las pensiones. ${ }^{38}$

\subsection{Principales censatarios del hospital y pautas de actuación}

Todos estos ejemplos nos presentan al hospital como una institución a la que acudían sobre todo individuos para solicitar pequeños créditos por asuntos más o menos cotidianos, pero ¿quiénes eran los principales vendedores de censales?, ¿de dónde procedían?, ¿cómo actuaban?, etc. Estas cuestiones nos ponen en relación con la sociología del crédito censal, esto es, con los protagonistas de este mercado de rentas.

Como ya se ha señalado, prácticamente la mayoría de censatarios eran vecinos de Teruel, labradores o artesanos y, en menor medida, miembros de la baja nobleza y clérigos, tal como ocurrió también en otros territorios de la Corona ${ }^{39} \mathrm{Y}$, como se desprende de la lectura atenta de la documentación, la mayoría de los deudores disponían de patrimonios modestos sobre los que cargaban sus censales.

Atendiendo a categorías sociales, el $70 \%$ de los vendedores de censales eran labradores, seguidos de lejos por un amplio sector de menestrales como pelaires, tejedores o incluso algún notario. Por su parte, cabe resaltar que la mayoría de estos labradores actuaron junto a sus esposas, constituyendo ambos la unidad básica de producción agrícola. ${ }^{40}$ De hecho, el $58 \%$ de operaciones estaban formadas por cónyuges, frente a un $24 \%$ de acciones individuales, que correspondían casi todas ellas a ventas de artesanos. Por otra parte, hay un

38 Sobre la cuestión de la morosidad, véase Furió (1998: 141-144).

39 Furió et alii (1993: 126-127) quienes introducen la interesante idea de la vinculación de los oficios artesanos al mundo rural y la compra-venta de censales.

40 Furió (1990: 307); quien además también analiza la composición del grupo doméstico en la Valencia bajomedieval, véase ibíd, pp. 312-316. 


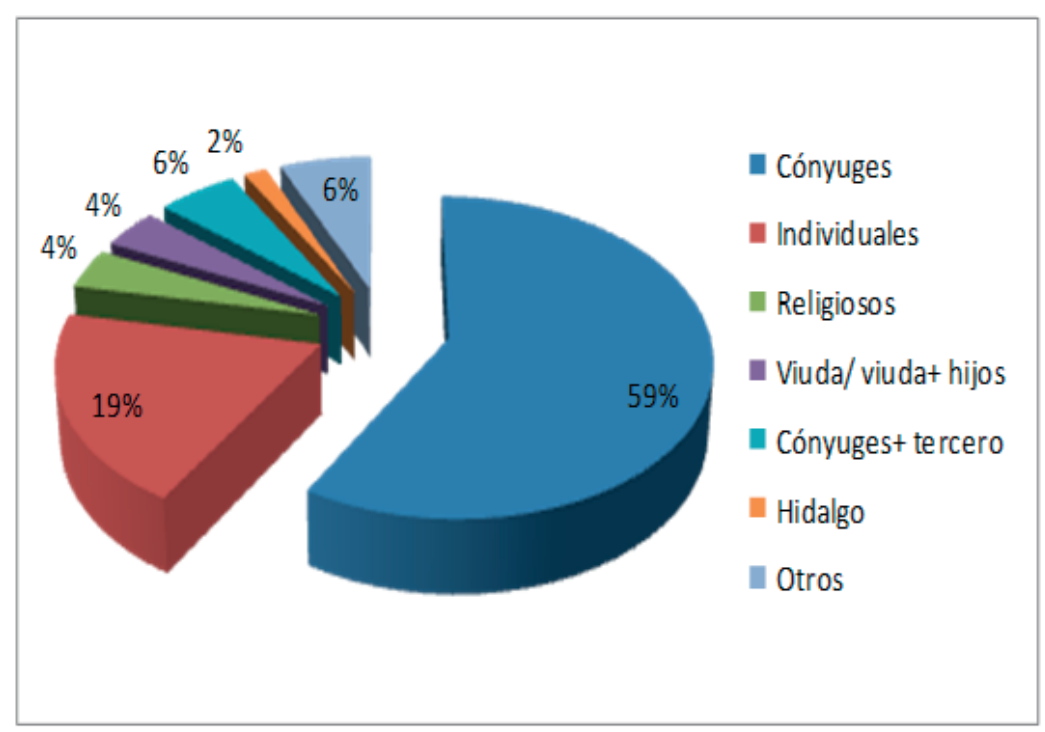

Gráfico 3. Condición social de los principales censalistas

pequeño porcentaje de créditos en el que encontramos a tres personas vinculadas, normalmente cónyuges, más algún vecino, la madre de uno de ellos, un hermano, etc. También aparecen viudas, pero en estos casos siempre actuando junto a sus hijos.

En alguna ocasión, observamos al mismo censatario vendiendo varios censales en momentos diferentes. Este es el caso de Antón de Barrachina, labrador, quien en 1504 vendió individualmente un censal por 100 s.j, y en 1510, junto a su mujer, otro por 310 s.j. Por su parte, Domingo Sánchez, labrador, el 9 de agosto de 1500 vendió junto a su mujer Juana un censal de 150 s.j., del que hizo quitación el 8 de diciembre de ese mismo año. Un año después, el 18 de diciembre de 1501, vendió otro censal del mismo precio. ${ }^{41}$

Por lo que respecta a la procedencia, también se documentan vecinos de las aldeas de Teruel que vendieron pensiones censales — de nuevo, casi todos

41 Más allá de quiénes vendían las rentas, resultaría interesante observar los lazos establecidos entre iguales a la hora de vender censales y las relaciones de confianza y seguridad que se tejían entre ellos, ya que - como se ha señalado anteriormente - , estas circunstancias reforzaban las actividades de crédito y las dotaban de cierto amparo y protección. 
ellos cónyuges - al hospital. Así, hallamos vendiendo censales a vecinos de Alfambra (seis documentados), Cella y Visiedo (con cuatro cada uno), Castralvo, Caudé y Villalba Baja (con tres), Celadas, Corbalán y Cubla (con dos), y Matas, Castant, Escorihuela, Orihuela del Tremedal, Puebla de Valverde, Torrelacárcel, Villalba Alta, Villalba la Jusana y Villel (con una venta respectivamente). Ello atestigua que el hospital era una institución a la que se acudía de lugares cercanos y gozaba de cierta fama en el entorno regional, ya que las operaciones extralocales supusieron en torno al $29 \%$ del total (38 casos). Además, cabe destacar que las poblaciones señaladas se encuentran generalmente en las cercanías de la ciudad, siendo los núcleos de Visiedo u Orihuela del Tremedal los más lejanos, con una distancia de 45 y $57 \mathrm{~km}$. respectivamente.

Por último, hay casos muy puntuales que merecen una mención especial, tales como los censales vendidos por clérigos, hidalgos y concejos. En cuanto al colectivo religioso, aparte del censal creado por la iglesia de san Jaime para la compra de las campanas, encontramos a otro clérigo de la misma iglesia actuando como particular, Pedro Fortún, quien el 17 de julio de 1514 recibió 300 s.j por una pensión anual de 25 s.j a pagar cada año el 16 de julio. Además, en el documento de venta se imponía una pena de $4 \mathrm{s.j}$. por cada retraso en la paga de la pensión y se establecía como garantía una tierra del clérigo en el término turolense.

Por su parte, en el volumen documentamos a dos hidalgos comprando censales. Así, en 1494, García de Heredia, junto a su mujer Francisca Cabrero, y al hermano del primero, Juan de Heredia, clérigo, vendieron un censal por precio de $300 \mathrm{~s} . j$ que cargaron sobre una casa de la ciudad y unas tierras de la rambla. El censal se amortizó en diciembre de 1510 y cabe señalar también que García de Heredia y su hermano Francisco, que compró otro censal en 1510, formaron parte de la administración del hospital en diversos periodos, siendo por ejemplo García de Heredia miembro de la junta y contador en diferentes anualidades entre 1485 y $1500 .^{42}$

Finalmente, resulta interesante la venta de un censal que el 16 de marzo de 1508 realizó el concejo de Peralejos, aldea situada a unos $20 \mathrm{~km}$. de Teruel. El concejo, congregado en el interior de la iglesia de san Bartolomé, vendió una pensión de $33 \mathrm{~s} .4 \mathrm{~d}$.j a pagar anualmente al hospital, so pena de un recargo de 3 s.j por cada retraso, por el precio de 400 s.j (un 8,33\% de interés). El censal 
se cargó sobre el horno del concejo y sobre todas las rentas y emolumentos de los vecinos de Peralejos. Con todo, este interesante ejemplo es la única muestra en el libro padrón del recurso municipal al préstamo censal que ofrecía el hospital y que tanto ha sido estudiado desde la perspectiva de la deuda pública. ${ }^{43}$

\section{Consideraciones finales}

Llegados a este punto, una vez presentada la función crediticia desempeñada por el hospital de san Juan Bautista, cabría reflexionar sobre varios asuntos que pueden resultar de especial interés para la historia de la institución.

Partiendo de la fuente, el libro padrón del notario Alfonso Jiménez, hemos podido comprobar cómo una documentación de estas características posibilita estudios de diversa índole relativos a la administración del hospital. Todo ello pese a no disponer, para este caso, de libros de cuentas que hubieran permitido ofrecer una panorámica más completa de la evolución de las finanzas del hospital. De haber sido así, se hubiese podido comprobar el peso que tuvo el recurso al crédito tanto por lo que respecta a los ingresos procedentes de las propias pensiones como a los gastos por compra de rentas. Dicho en otras palabras, los libros de cuentas permitirían conocer qué cantidades se destinaban al préstamo y que suponían en total estas pensiones acumuladas, así como la capacidad de la institución para reinvertir nuevos ingresos en la adquisición de más rentas. Pese a todo, las posibilidades de estudio de una fuente como la analizada son todavía muy amplias y, al igual que en este caso nos hemos centrado en la actividad censal propiamente dicha, hubiera sido de gran interés analizar con más profundidad a los vendedores de rentas y, a través de ellos, conocer un poco más el paisaje agrario turolense por ejemplo, ya que - como hemos señalado - las ventas nos facilitan información sobre las parcelas de tierras sobre las que se carga el censal. ${ }^{44}$

Por lo que aquí respecta, la documentación analizada sí que ha permitido poner de relieve la función del hospital como institución de «crédito caritati-

43 Para Aragón, véase: Falcón (1997: 239-273); Abella (2009: 47-64); Sesma (1979: 171-202). Y más en concreto, un estudio reciente con amplia bibliografía y cuestión historiográfica en Laliena (2014: 147-177). Otra síntesis actual sobre el mercado de la deuda pública en la Cataluña bajomedieval, con especial hincapié en la consolidación del mercado de la deuda censal y los agentes financieros en Verdés (2014: 252 y sig.).

44 Muñoz (1991). 
vo»: un crédito -como hemos visto - a corto plazo y fundamentalmente local, que siguió unos patrones similares, tanto por las características de los préstamos como por los censatarios, a los observados para otros territorios de la Corona de Aragón. Efectivamente, los censales vendidos por el hospital permitieron a numerosos campesinos y artesanos de Teruel hacer frente a pequeños gastos ineludibles. Sin duda, esta forma de préstamo a corto-medio plazo parece que fue muy utilizado para subvenir a gastos ordinarios y no tan ordinarios a los que se enfrentaban estas gentes en su vida cotidiana. El recurso al crédito posibilitaba a los censatarios seguir desarrollando su labor y también les facilitaba las inversiones productivas, un hecho que sirve para matizar tal como se ha puesto de manifiesto en los últimos tiempos - la visión negativa que se tenía sobre esta forma de endeudamiento. De todas formas, para disponer de una visión integral, sería asimismo interesante atender a otras formas de crédito a corto plazo a las que igualmente acudirían estos agentes y que no han dejado rastro documental conocido. ${ }^{45}$

Finalmente, más allá del tema del crédito, el ejemplo que nos ofrece el hospital de san Juan Bautista y santa María de Villaespesa en relación con la ciudad, es el de una institución plenamente integrada en el mercado financiero que pronto pasaría a ser controlada por el municipio. Regresamos de esta forma a la idea inicial de la beneficencia y la caridad realizada y mediatizada desde el poder público, situando la institución analizada dentro de la trama fiscal y financiera bajomedieval y moderna.

Para un estudio actual sobre otras formas de crédito de la sociedad rural, aparte de los numerosos análisis de J.V. García Marsilla o A. Furió, véase Viciano (2013: 13-44), quien trata sobre las obligaciones en la sociedad rural y analiza en profundidad que supone esta actividad en un marco concreto y limitado; Asimismo: Salrach (2004) y Furió (1995: 887-919). 


\section{Apéndices}

\section{Cuadro 2. Emisión/luición de los censales documentados}

\begin{tabular}{|c|c|c|c|c|}
\hline $\begin{array}{l}\text { Fecha de } \\
\text { venta }\end{array}$ & $\begin{array}{c}\text { Fecha de } \\
\text { luición }\end{array}$ & $\begin{array}{c}\text { Capital } \\
(s . j)\end{array}$ & $\begin{array}{l}\text { Pensión censal } \\
\text { (en sueldos } \\
\text { y dineros } \\
\text { jaqueses) }\end{array}$ & Vendedor \\
\hline $1483 / 07 / 21$ & $1488 / 09 / 14$ & 120 & $10 \mathrm{~s}$ & $\begin{array}{l}\text { Pedro Lidón } \\
\text { y Catalina Pérez, cónyuges }\end{array}$ \\
\hline $1483 / 12 / 14$ & $1505 / 02 / 05$ & 100 & $8 \mathrm{~s} 4 \mathrm{~d}$ & $\begin{array}{l}\text { Jimeno Cañegral } \\
\text { y Catalina Esteban, cónyuges }\end{array}$ \\
\hline $1485 / 04 / 26$ & $1514 / 09 / 29$ & 100 & $8 \mathrm{~s} 4 \mathrm{~d}$ & $\begin{array}{l}\text { García Montañés } \\
\text { y Armisena Villaespesa, cónyuges }\end{array}$ \\
\hline $1486 / 02 / 23$ & $10 / 08 / 1510$ & 460 & $38 \mathrm{~s} 4 \mathrm{~d}$ & $\begin{array}{l}\text { Jaime Esteban } \\
\text { y Juana Bernat, cónyuges }\end{array}$ \\
\hline $1486 / 06 / 27$ & $1507 / 09 / 05$ & 50 & $4 \mathrm{~s} 2 \mathrm{~d}$ & Juan Escudero \\
\hline $1486 / 10 / 28$ & $1490 / 05 /$ & 110 & $9 \mathrm{~s} 2 \mathrm{~d}$ & $\begin{array}{l}\text { Juan de Valtueña, infanzón } \\
\text { y Juana Pérez, cónyuges }\end{array}$ \\
\hline $1487 / 02 / 18$ & $1494 / 06 / 29$ & 100 & $8 \mathrm{~s} 4 \mathrm{~d}$ & $\begin{array}{l}\text { Juan de Montiel, sastre } \\
\text { y Armisena Genés, cónyuges }\end{array}$ \\
\hline $1488 / 05 / 22$ & $1492 / 02 / 03$ & 100 & $8 \mathrm{~s} 4 \mathrm{~d}$ & $\begin{array}{l}\text { Pascual Genés } \\
\text { y Quietria Maestro, cónyuges }\end{array}$ \\
\hline $1488 / 02 / 22$ & $17 / 09 / 1514$ & 100 & $8 \mathrm{~s} 4 \mathrm{~d}$ & $\begin{array}{l}\text { Antonio del Mesado, labrador, } \\
\text { y Elvira de Sos, cónyuges }\end{array}$ \\
\hline 1491/09/11 & $1517 / 03 / 17$ & 100 & $8 \mathrm{~s} 4 \mathrm{~d}$ & $\begin{array}{l}\text { Sancho Cabrerizo, cestero } \\
\text { y Lorenza Valero, cónyuges }\end{array}$ \\
\hline 1494/04/03 & $1510 / 11 / 12$ & 300 & $25 \mathrm{~s}$ & $\begin{array}{l}\text { García de Heredia, hidalgo, Fran- } \\
\text { cisca Cabrero, cónyuges } \\
\text { y Juan de Heredia, clérigo } \\
\text { y hermano del primero }\end{array}$ \\
\hline 1494/08/03 & $1515 / 01 / 17$ & 100 & $8 \mathrm{~s} 4 \mathrm{~d}$ & $\begin{array}{l}\text { Gil de Barrachina } \\
\text { y Catalina Crespo, cónyuges }\end{array}$ \\
\hline $1495 / 03 / 24$ & $1517 / 03 / 15$ & 150 & $12 \mathrm{~s} 6 \mathrm{~d}$ & $\begin{array}{l}\text { Jimeno Asensio, labrador } \\
\text { y Francisca Navarro, cónyuges }\end{array}$ \\
\hline $1495 / 06 / 24$ & $1508 / 02 / 28$ & 200 & $16 \mathrm{~s} 8 \mathrm{~d}$ & $\begin{array}{l}\text { Juan Gómez, tejedor } \\
\text { y Marco Esteban, labrador }\end{array}$ \\
\hline
\end{tabular}


Esther Tello Hernández

\begin{tabular}{|c|c|c|c|c|}
\hline 1497/03/05 & $1499 / 10 / 03$ & 100 & $8 \mathrm{~s} 4 \mathrm{~d}$ & $\begin{array}{l}\text { Antonio Lorent, clérigo de san } \\
\text { Salvador,y Juan Lorent, labrador, } \\
\text { hermanos }\end{array}$ \\
\hline 1497/08/02 & $1511 / 08 / 03$ & 160 & $13 \mathrm{~s}$ & $\begin{array}{l}\text { Martín de Fumbuena } \\
\text { y Francisca Asensio, cónyuges } \\
\text { (vecinos de Castralvo) }\end{array}$ \\
\hline $1497 / 08 / 20$ & $1514 / 10 / 01$ & 150 & $12 \mathrm{~s} 6 \mathrm{~d}$ & $\begin{array}{l}\text { Marco Esteban, labrador } \\
\text { y Catalina Gil, cónyuges }\end{array}$ \\
\hline $1497 / 08 / 20$ & 1508/01/08 & 100 & $8 \mathrm{~s} 4 \mathrm{~d}$ & $\begin{array}{l}\text { Pedro de Orrios } \\
\text { y su hijo, labrador }\end{array}$ \\
\hline 1500/08/09 & $1500 / 12 / 08$ & 150 & $12 \mathrm{~s} 6 \mathrm{~d}$ & $\begin{array}{l}\text { Domingo Sánchez, labrador, } \\
\text { y Juana Miguel, cónyuge }\end{array}$ \\
\hline $1500 / 08 / 30$ & $1512 / 11 / 11$ & 100 & $8 \mathrm{~s} 4 \mathrm{~d}$ & Luis Galcerán, labrador \\
\hline $1500 / 10 / 03$ & $1517 / 01 / 24$ & 150 & 12 s $6 \mathrm{~d}$ & $\begin{array}{l}\text { Catalina de Galve, viuda de Pedro } \\
\text { Martín de Collados, su hijo Pedro } \\
\text { y su esposa Juana } \\
\text { (vecinos de de Caudé) }\end{array}$ \\
\hline $1502 / 02 / 12$ & $1506 / 04 / 02$ & 400 & $33 \mathrm{~s} 14 \mathrm{~d}$ & $\begin{array}{l}\text { Vicente de Fumbuena, labrador, } \\
\text { y su hijo Vicente } \\
\text { (vecinos de Castralvo) }\end{array}$ \\
\hline $1502 / 12 / 18$ & $1511 / 12 / 08$ & 120 & $10 \mathrm{~s}$ & $\begin{array}{l}\text { Francisco Lorenzo, labrador, } \\
\text { y su esposa Catalina Nadal }\end{array}$ \\
\hline $1503 / 10 / 27$ & $1507 / 11 / 08$ & 200 & $16 \mathrm{~s} 8 \mathrm{~d}$ & $\begin{array}{l}\text { Domingo Pascual } \\
\text { (clérigo de Cella) } \\
\text { y Juan Conejo (vecino de Celadas) }\end{array}$ \\
\hline $1505 / 08 / 01$ & $1514 / 04 / 04$ & 100 & $8 \mathrm{~s} 4 \mathrm{~d}$ & $\begin{array}{l}\text { Pedro Asensio, labrador, } \\
\text { y su esposa Guisabel Sánchez }\end{array}$ \\
\hline $1505 / 09 / 02$ & $1514 / 05 / 14$ & 100 & $8 \mathrm{~s} 4 \mathrm{~d}$ & $\begin{array}{l}\text { Juan de Barrachina } \\
\text { y su esposa Guisabel de Ovón }\end{array}$ \\
\hline 1507/11/10 & $1512 / 07 / 17$ & 200 & 16 s $8 d$ & $\begin{array}{l}\text { Antón Muñóz } \\
\text { y su esposa Bartolomea Escrig }\end{array}$ \\
\hline $1508 / 03 / 16$ & $1512 / 03 / 18$ & 400 & $33 \mathrm{~s} 4 \mathrm{~d}$ & $\begin{array}{l}\text { El concejo de Peralejos, } \\
\text { aldea de Teruel }\end{array}$ \\
\hline 1508/06/04 & $1509 / 09 / 12$ & 100 & $8 \mathrm{~s} 4 \mathrm{~d}$ & $\begin{array}{l}\text { Francscisco Balvastro, esparteño } \\
\text { y su esposa Catalina Escudero }\end{array}$ \\
\hline
\end{tabular}


La actividad crediticia de un hospital turolense a través de la compra de censales (1482-1517)

\begin{tabular}{|c|c|c|c|c|}
\hline $1510 / 03 / 13$ & $1511 / 12 / 13$ & 300 & $25 \mathrm{~s}$ & $\begin{array}{l}\text { Francisco Sánchez } \\
\text { (vecino de Alfambra) }\end{array}$ \\
\hline $1510 / 08 / 28$ & $1514 / 04 / 17$ & 200 & 16 s $8 d$ & $\begin{array}{l}\text { Juan Balvastro, labrador, } \\
\text { su esposa Catalina de Soria, } \\
\text { y Martín Balvastro, hermano } \\
\text { del primero }\end{array}$ \\
\hline $1511 / 03 / 01$ & $1520 / 03 / 02$ & 400 & $33 \mathrm{~s} 4 \mathrm{~d}$ & $\begin{array}{l}\text { Miguel Jordán } \\
\text { (vecino de Alfambra) }\end{array}$ \\
\hline $1512 / 02 / 17$ & $1516 / 12 / 22$ & 150 & $12 \mathrm{~s} 6 \mathrm{~d}$ & $\begin{array}{l}\text { Simon Calvo, tejedor } \\
\text { y su esposa Francisca de las } \\
\text { Cuevas }\end{array}$ \\
\hline $1512 / 12 / 14$ & $1513 / 11 / 08$ & 100 & $8 \mathrm{~s} 4 \mathrm{~d}$ & $\begin{array}{l}\text { Pedro de Pedro de Orrios, labrador, } \\
\text { y su esposa Catalina de Campos }\end{array}$ \\
\hline $1514 / 01 / 08$ & $1515 / 07 / 22$ & 200 & $16 \mathrm{~s} 8 \mathrm{~d}$ & Juan de Riglos, tejedor \\
\hline $1514 / 04 / 11$ & $1517 / 02 / 18$ & 600 & $50 \mathrm{~s}$ & $\begin{array}{l}\text { Bartolomé Maicas } \\
\text { y su esposa Pascuala Pérez } \\
\text { (vecinos de Villel) }\end{array}$ \\
\hline $1514 / 05 / 28$ & $1517 / 01 / 11$ & 200 & 16 s $8 d$ & $\begin{array}{l}\text { Juan Lorenzo, labrador, } \\
\text { y su esposa María de Fumbuena }\end{array}$ \\
\hline $1514 / 09 / 26$ & $1515 / 06 / 03$ & 150 & $12 \mathrm{~s} 6 \mathrm{~d}$ & $\begin{array}{l}\text { Juan Andrés } \\
\text { y su esposa Catalina Navarro }\end{array}$ \\
\hline $1514 / 10 / 12$ & $1518 / 01 / 08$ & 300 & $25 \mathrm{~s}$ & $\begin{array}{l}\text { Benedicto Martín } \\
\text { (vecino de Visiedo) }\end{array}$ \\
\hline $1514 / 11 / 24$ & $1525 / 01 / 16$ & 600 & $42 \mathrm{~s}$ & $\begin{array}{l}\text { Francisco Martinez Tejadillos, hos- } \\
\text { talero (de la Puebla de Valverde) } \\
\text { y Pascuala }\end{array}$ \\
\hline $1515 / 02 / 14$ & $1515 / 03 / 02$ & 500 & 41 s $8 d$ & $\begin{array}{l}\text { Antón Martínez } \\
\text { y su esposa Pascuala Ferrero } \\
\text { (vecinos de Cella) }\end{array}$ \\
\hline $1515 / 05 / 31$ & $1517 / 10 / 10$ & 100 & $8 \mathrm{~s} 4 \mathrm{~d}$ & Domingo Montón, labrador \\
\hline $1517 / 09 / 29$ & $1518 / 02$ & 350 & $29 \mathrm{~s} 2 \mathrm{~d}$ & $\begin{array}{l}\text { Miguel del Povo, } \\
\text { y su esposa María Sánchez } \\
\text { (vecinos de Caudé) }\end{array}$ \\
\hline
\end{tabular}




\section{Referencias bibliográficas}

ABELLA, J. (2009), «La Deuda pública de los municipios aragoneses en los siglos XIV y XV», Anuario de Estudios Medievales, nº 39/1, 47-64.

ATIENZA,A. (1987), «El préstamo en la sociedad tardofeudal: las rentas censales del clero regular zaragozano en el siglo XVIII», Revista de Historia Jerónimo Zurita, $\mathrm{n}^{\circ} 55,67-104$.

AVALLONE, P. (2007), «Il credito su pegno nel Regno di Napoli», en P. Avallone (ed.), Prestare ai Poveri. Il credito su pegno e i Monti di Pietà in area Mediterranea (secoli XV-XIX), Napoli, Consiglio Nazionale delle Ricerche, Istituto di Studi sule Società del Mediterraneo, 69-101.

AVENTÍN, M. (2014), «Mercat de rendes, mercat de salvació», en M. Aventín, Vivéncies $i$ sentiment de la mort: microanálisis de families $i$ comunitats rurals en temps feudals, Barcelona, PangurBàn, 53-73. (Publicado originariamente en: SÁNCHEZ, M. (ed.) (1993), Estudios sobre renta, fiscalidad y finanzas en la Cataluña bajomedieval, Barcelona, CSIC, 133-151).

- (1996), La societat rural a Catalunya en temps feudals, Vallès oriental, segles XIII-XVI, Barcelona, Columna Edicions.

BERTHE, M. (ed.) (1998), Endettement paysan et crédit rural dans l'Europe médiévale et moderne. Actes des XVIIes Journées Internationales de l'Abbaye de Flaran, Toulouse, Presses Universitaires du Mirail.

BERTRAN, P. (2013), «La Pia Almoina de Lleida i el recurs al crèdit censal com a Font de finançament al voltant de 1400», en J. Mutgé; R. Salicrú; C. Velna (eds.) La Corona catalanoaragonesa, l'islam i el món mediterrani: estudis d'història medieval en homenatge a la doctora Maria Teresa Ferrer i Mallol, Barcelona, Consejo Superior de Investigaciones Científicas, 87-97.

BONFIELD, C.; REINARZ, J.; HUGUET, T. (eds.) (2013), Hospitals and Communities, 1100-1960, Oxford, Peter Lang print.

CASTAÑO, J. (2007), «Crédito caritativo en la Castilla de mediados del siglo XV, los estatutos de las Arcas de Misericordia y la usura judía», en P. Avallone (ed.), Prestare ai Poveri. Il credito su pegno e i Monti di Pietà in area Mediterranea (secoli $X V$-XIX), Napoli, Consiglio Nazionale delle Ricerche, Istituto di Studi sule Società del Mediterraneo, 101-143.

COMELLES, J.M. (2014), «Hospitals, Political Economy and Catalan Cultural Identity», C. Bonfield; J. Reinarz; T. Huguet (eds.), Hospitals and Communities, 11001960, Oxford, Peter Lang print., 183-209.

CONEJO, A. (2013), «The Study of Medieval Hospitals: an Ongoing History», SVMMA. Revista de Cultures Medievals, vol. 2, iii-vi.

- (2010), «La financiación de los hospitales de la Corona de Aragón durante la baja edad media: condiciones sociales, económicas y espirituales», en S. Cavaciocchi (ed.), Le interazioni fra economia e ambiente biologico nell'Europa preindustria- 
le. Secc. XIII-XVII. Atti della Quarantesima Settimana di Studi, Firenze, Fondazione Istituto Internazionale di Storia Economica F. Datini, Firenze University Press, 2010, 437-445.

FALCÓN, M.I. (1997), «Finanzas y fiscalidad de ciudades, villas y comunidades de aldeas aragonesas», en Finanzas y fiscalidad municipal. V Congreso de Estudios Medievales, León, 239-273.

FERRER, Ll. (1986), «L'Església com a institució de crèdit: les quotidianes distribucions de la Seu de Manresa els segles XVIII i XIX», Recerques: historia, economía, cultura, $\mathrm{n}^{\mathrm{o}} 18,7-46$.

(1983), «Censals, vendes a carta de gràcia i endeutament pagès al Bages (s. XVIII)», Estudis d'història agrària, $\mathrm{n}^{\mathrm{o}}$ 4, 101-128.

FERRER, Ll. FURIÓ, A. (1990), «Tierra, familia y transmisión de la propiedad en el país valenciano durante la Baja Edad Media», en R. Pastor (coord.), Relaciones de poder, de producción y parentesco en la Edad Media y Moderna. Aproximación a su estudio, Madrid, Consejo Superior de Investigaciones científicas, 305-329.

FURIÓ, A. (1998), «Endettement paysan et crédit dans la Péninsule Ibérique au bas Moyen Âge», en M. Berthe (ed.), Endettement paysan et crédit rural dans l'Europe médiévale et moderne. Actes des XVIIes Journées Internationales de l'Abbaye de Flaran, Toulouse, Presses Universitaires du Mirail, 139-168.

- (1995), «El mercado de la tierra en el País Valenciano a finales de la Edad Media», Hispania, $\mathrm{n}^{\circ} 191,887-919$.

- (1993), «Crédito y endeudamiento: el censal en la sociedad rural valenciana (siglos XIV-XV)», en E. Sarasa; E. Serrano (eds.), Señorío y feudalismo en la Península Ibérica, Zaragoza, Institución Fernando el Católico, vol. I, 501-534.

FURIÓ, A. FURIÓ, A.; GARCÍA MARSILLA, J.V; MIRA, A.J.; VERCHER, S.; VICIANO, P. (1993), «Endeutament i morositat en una comunitat rural. El censal a Sueca a finals del segle XV», en Actes de la V Assemblea d'Història de la Ribera, (Almussafes, 1988), Almussafes, Ajuntament, 160-165.

GALERA, A. (1997), «Estudi del procés seguit contra el rector Romeu de Fontelles per robatori comès en l'església parroquial de Sant Miquel de la vila de Cardona l'any 1421», XXXIX Assemblea Intercomarcal d'Estudiosos (Cardona, 22 i 23 d'octubre de 1994), Cardona, Patronat Municipal de Museus, vol. II, 11-45.

GALLENT, M. (1984), «Instituciones hospitalarias y poderes públicos en Valencia», Saitabi: revista de la Facultat de Geografia i Història, $\mathrm{n}^{\circ}$ 34, 75-88.

GARCÍA MARSILLA, J.V. (2002), Vivir a crédito en la Valencia Medieval: de los orígenes del sistema censal al endeudamiento del municipio, Valencia, Universitat de Valencia.

GARGAllo, A. (1997-2005), El Concejo de Teruel en la Edad Media, 1177-1327, Teruel, Instituto de Estudios Turolenses, 4 vol.

GAZZINI, M. (2012), «Ospedali nell'Italia medievale», Reti Medievali, $\mathrm{n}^{\circ} 13-1$ (2012), 211-237. 
HERNANDO, J. (2007), «Les controvèrsies teològiques sobre la licitud del crèdit a llarg termini», en M. Sánchez (ed.), El món del crèdit a la Barcelona Medieval, Barcelona, Quaderns d'història, 213-238.

HUGUET, T. (2014), «Speculum hospitalis, speculum civitatis. ¿Por qué estudiar la historia de los hospitales?», en T. Huguet et alii (coords.), Ciudad y hospital en el occidente europeo, 1300-1700, Lleida, Milenio, 13-27.

HUGUET, T.; VERDÉS, P.; ARRIZABALAGA, J.; SÁNCHEZ, M. (coords.) (2014), Ciudad y hospital en el occidente europeo, 1300-1700, Lleida, Milenio.

KUSMAN, D. (2012), «Le rôle de l'Èglise comme institution dans la contractualisation des opérations de crédit en Brabant, XIII-XV siècle», en F. Ammannati (ed.), Religione e istituzioni religiose nell'economia europea. 1000.1800. Atti della Quarantatreesuma Settimana di Studi, Firenze, Fondazione Istituto Internazionale di Storia Economica F. Datini, Firenze University Press, 227-249.

LALIENA, C. (2014), «Crisis tempranas de la deuda municipal en el Bajo Aragón: Monroyo, 1346», en J.A. Sesma; C. Laliena (Coords.), De la escritura a la Historia (Aragón, siglos XIII-XV), Zaragoza, Grupo CEMA-Colección Garba, 147-177.

LATORRE, J.M. (2010), «Producción, rendimientos y renta agraria en Teruel: las propiedades del hospital de la Asunción (1771-1832)», Investigaciones Históricas, $\mathrm{n}^{\circ} 30,71-98$.

- (1992), Economía y religión. Las rentas de la catedral de Huesca y su distribución social (siglos XVI-XVII), Zaragoza/Huesca, Institución Fernando el Católico/Instituto de Estudios Altoaragoneses.

LINDGREN, U. (1987), «¿De qué vivían los hospitales? Los fundamentos económicos de los hospitales de Barcelona de 1375 a 1500», Anuario de Estudios Medievales, $\mathrm{n}^{\circ} 17,525-532$.

MATEOS, J.A. (1999), «Municipio y crédito en el Aragón Moderno: el endeudamiento censal del concejo darocense (siglo XVI-XVII)», Espacio, Tiempo y Forma. Serie IV. Historia Moderna, ${ }^{\circ}$ 12, 67-89.

MONTERDE, C. (2008), «Las ordinaciones del hospital de Nuestra Señora de Gracia de Zaragoza establecidas por don Alfonso de Aragón, arzobispo de Zaragoza y lugarteniente general del reino», Aragón en la Edad Media, nº 20, 505-528.

MORELLÓ, J. (en prensa), «Agli albori dell'istituzionalizzazione del microcredito sui cereali: l'insediamento delle Arcas di misericordia e dei pósitos municipali nel Basso Medioevo ispanico», en M. Carboni; M.G. Muzzarelli (dir.), Monti frumentari e altre forme di credito non monetario fra Medioevo ed Età Contemporanea, Bologna-Ravenna, Centro Studi sui Monti di Pietà e sul Credito Solidaristico.

- (2014), «Finanzas hospitalarias y deuda pública: los censales de la Santa Creu de Barcelona en torno a 1500», en T. Huguet et alii (coords.), Ciudad y hospital en el occidente europeo, 1300-1700, Lleida, Milenio, 211-261. 
MUÑOZ, V. (2006), «Desarrollo espacial del arrabal de Teruel en la Baja Edad Media», Stvidum. Revista de Humanidades, nº 12, 193-207.

- (1991), Economía y sociedad en los siglos XIV, XV y XVI en la ciudad de Teruel: rentas, propiedades e influencia social de la iglesia turolense, Tesis-Universidad de Zaragoza. Facultad de Filosofía y Letras.

MUZZARELLI, M.G. (2010), «I Monti di Pietà: le cure prestate e quelle richieste», Italia Francescana, $\mathrm{n}^{\circ} 85,101-111$

- (2005), Sacri recinti del credito. Sedi e storie dei Monti di pietà in Emilia-Romagna, Venezia, Marsilio.

NAVARRO, G. (2006), «El campesinado turolense del siglo XV», Aragón en la Edad Media, $\mathrm{n}^{\mathrm{o}} 19,417-462$.

- (2000), «El hospital de Santa María de Villaespesa y de San Juan Bautista en la ciudad de Teruel a través de los actos notariales de Alfonso Jiménez (1481-1518)», Aragón en la Edad Media, XVI, 565-590.

ORTÍ, P. (2007), «Les finances municipals de Barcelona dels segles XIV i XV: del censal a la Taula de Canvi», en M. Sánchez (ed.), El món del crèdit a la Barcelona Medieval, Barcelona, Quaderns d'història, 257-282.

PASTORE, A.; GARBELLOTTI, A. (eds.) (2001), L'uso del denaro: patrimonio e amministrazione nei luoghi pii e negli enti ecclesiastici in Italia (secoli XV-XVIII), Bologna, Il Mulino.

PÉREZ, C. (2013), «Los grandes hospitales urbanos en Aragón en el siglo XV: Nuestra Señora de la Esperanza en Huesca y Nuestra Señora de Gracia en Zaragoza», en F. Ammannati (ed.), Assistenza e solidarietà in Europa, secc. XIII-XVIII. Atti della Quarantaquattresima Settimana di Studi, Firenze, Fondazione Istituto Internazionale di Storia Economica F. Datini, Firenze University Press Firenze, Firenze University Press, 292-294.

PICCINNI, G. (2012), Il banco dell'ospedale di Santa Maria della Scala e il mercato del denaro nella Siena del trecento, Pisa, Pacini.

- (2012), «Conti correnti di donne presso l'ospedale senese di Santa Maria della Scala. Interessi, patti, movimenti di denaro (1347-1377)», en G. Petti; P. Guglielmotti (eds.), Dare credito alle donne. Presenze femminili nell'economia tra medioevo ed età moderna (Convegno internazionale di studi. Asti, 8-9 ottobre 2010), Asti, Centro studi Renato Bordone sui Lombardi, sul credito e sulla banca, 121149.

- (2010), «El Hospital como empresa de la caridad pública (Italia, siglos XIII-XV)», en Ricos y Pobres: opulencia y desarraigo en el Occidente medieval. XXXVI Semana de Estudios Medievales de Estella, Pamplona, Gobierno de Navarra, 87-103.

REIXACH, A. (2003), «Censals i dots: mercats financiers i matrimonis en una ciutat catalana baixmedieval (Girona, 1340-1440», en Familia a la baixa edat mitjana (s. XIII-XV). Actes del III Seminari d'Estudis Medievals d'Hostalric, Hostalric, Ajuntament d'Hostalric, 49-66. 
RODRIGO, M.L. (1995), «Poder municipal y acción benéfico-asistencial. El Concejo de Daroca, 1400-1526», Aragón en la Edad Media, n 12, 287-317.

RUBIO, A. (1984), Pobreza, enfermedad y asistencia hospitalaria en la Valencia del siglo XIV, Valencia, Institución Alfonso el Magnánimo- Diputación Provincial.

RUBIO, D. (2007), «El circuit privat del censal a Barcelona», en M. Sánchez (ed.), El món del crèdit a la Barcelona Medieval, Barcelona, Quaderns d'història, 239-255.

SALRACH, J.M. (2004), «Mercat i mercats», en J.M. Salrach (coord.), Història agraria dels Països Catalans, Barcelona, Fundació catalana per la Recerca, vol. II, 395-432.

SÁNCHEZ, M. (2014), «Las cuentas de un hospital medieval: la Santa Creu de Barcelona (1430-1431)», en T. Huguet et alii (coords.), Ciudad y hospital en el occidente europeo, 1300-1700, Lleida, Milenio, 177-211.

SESMA, J.A. (2013), «Transformación social y revolución comercial en Aragón durante la Baja Edad Media», en Revolución comercial y cambio social: Aragón y el mundo mediterráneo (siglos XIV-XV), Zaragoza, Prensas de la Universidad de Zaragoza, 43-95.

- (1979), «Trayectoria económica de la Hacienda del reino de Aragón en el siglo XV», Aragón en la Edad Media, n 2, 171-202.

TELLO ARAGAY, E. (1994), «El papel del crédito rural en la agricultura del Antiguo Régimen: desarrollo y crisis de las modalidades crediticias (1600-1850)», Noticiario de Historia Agraria, $\mathrm{n}^{\circ}$ 7, 9-37.

TELLO HERNÁNDEZ, E. (2013), Aportación al estudio de las cofradías medievales y sus devociones en el reino de Aragón, Zaragoza, Institución Fernando el Católico.

TODESCHINI, G. (2007), «Credibilità, fiducia, richezza: il credito caritativo come forma della modernizzazione económica europea», en P. Avallone (ed.), Prestare ai Poveri. Il credito su pegno e i Monti di Pietà in area Mediterranea (secoli XV$X I X)$, Napoli, Consiglio Nazionale delle Ricerche, Istituto di Studi sule Società del Mediterraneo, 17-31.

- (2004), Ricchezza francescana. Dalla povertà volontaria alla società di mercato, Bologna, Il Mulino.

VICIANO, P. (2013), «Endeudarse para consumir. La función económica de las obligaciones en una villa rural valencia (Castellón de la Plana en 1499)», Historia agraria: Revista de agricultura e historia rural, $\mathrm{n}^{\circ}$ 61, 13-44

- (1991), «La gestió económica d'un monestir cistercenc femení: la Saïda de València a la fi del segle XV», Revista d'historia medieval, $\mathrm{n}^{\circ} 2$, 111-132.

VERDÉS, P. (2015): «El mercado de la deuda pública en la Cataluña de los siglos XIV-XV», Estados y mercados financieros en el Occidente cristiano (siglos XIIIXVI). Actas de la XLI Semana de Estudios Medievales de Estella. 15 al 18 de julio de 2014, Pamplona, Gobierno de Navarra, 243-271. 